\section{A Framework For Assessing Transport Information Systems Policies}

\author{
by Thierry Verduijn and Roel ter Brugge, \\ TNO Inro, Delft, and Hans Voordijk, Uni- \\ versity of Twente
}

The integration of information and communication services in transport can be a powerful opportunity to achieve transport policy goals. To ensure maximum benefit from these opportunities offered by information and communication services there is a need to create the conditions for adequate and widespread use of these services in transport. To support policy makers in the identification of policy requirements, i.e. necessary policy actions and measures, a policy assessment framework has been developed and applied. The framework is based on a "stagist" model in which the analysis of complex relationships between transport, information technology and policy is split into ten steps. In each step the framework addresses the most important aspects and mechanisms to be taken into account when defining policy for the integration of information and communication services.

\section{Introduction}

Information and communication services can contribute significantly to a safe, efficient and effective transport system. Through these services users will receive more reliable, complete and up to date information, allowing them to improve or extent current transport operations and processes. To ensure maximum benefit from the opportunities offered by information and communication services, conditions for adequate and widespread use of these services in transport have to be created. From a policy perspective, integration has a policy function and can be seen as an instrument that policy makers can use to achieve the objectives of the transport policy. In the TRANSINPOL (Transport Information Systems Policies)-project for DG TREN conditions for such an approach were assessed.
However, the definition of these conditions and the formulation of policies to achieve them is not easy. The identification of the needs for favourable conditions and defining effective policies is difficult because of the following factors:

- The pace of development of information technologies is very high;

- There are many actors and stakeholders in the transport sector as well as in the ICTindustry;

- Most of the developments in information technology take place outside the transport sector and can hardly be influenced;

- The conditions should not only fulfil current needs of specific actors or systems in the transport sector, but should contribute to a more efficient and effective transport system in the long term and therefore also assist future transport policies and options.

To handle these complexities, a conceptual framework has been developed and applied in the TRANSINPOL-project, funded by the European Commission (TNO et al. 1999). This framework addresses the most important aspects and mechanisms to be taken into account when defining policies for the integration of information and communication services from a transport perspective. Basis for this framework is a "stagist" model in which the policy making process is divided up in several steps or stages. The strength of this approach is that it provides a rational structure within we may consider the multiplicity of reality. By applying this framework, the most pressing policy requirements have been identified.

The aim of this paper it to discuss the elements of the framework and potential future extensions. The outline of this paper is as follows. First, the multiplicity of relations between transport, information technology and policy and the theoretical background of "stagist" models is discussed. Second, the conceptual framework and its components are presented. Then, the application of the framework in the TRANSINPOL-project is discussed. Concluding remarks and recommendations for future extensions are presented in the final section. 


\section{Transport, ict and transport policy}

The major purpose to develop a conceptual framework for policy assessment is to give insight on the one hand in the drivers of the integration of ICT in transport, and on the other hand how integration can be influenced by the public sector and in particular by the EU. In the field of information, communication and navigation technologies in transport policy makers have to consider five main elements for the assessment of policy requirements (TNO et al. 1999):

- the transport sector, characterised by a wide variety of actors and markets. Each group of actors has typical needs for integration of information, communication and navigation technologies, that result from the objectives of the actors and the dynamics of the markets in which they are operating.

- information, communication and navigation technologies, the development of these technologies is generally driven by non-transport markets, resulting in new generic products in terms of systems or services which can be used directly or indirectly for transport purposes. Trends in availability, performance, reliability, costs, sustainability and basic functionality of these technologies are of particular importance for the assessment of policy requirements.

- $\quad$ generic transport telematic services group together telematics systems and services which have the same transport functionality. All possible sertvices are reduced to eight categories of generic TT-services have been identified: market information, transaction, operations management, navigation, traffic information, traffic management and others, like dangerous goods, customs, etc. Approaching the subject through services is considered to be an important step, since it emphasise functions and actors instead of technologies (see Figure 1).
- Common Transport Policy: the relevance or impact of the integration of information and communication services is determined by evaluating the contribution to the CTP objectives.

- integration: integration is defined as the introduction and wide spread use of $\dot{\mathbf{n}}$ formation and communication services, systems and technologies in transport. Integration can be defined at two levels: technology integration, i.e. how can technologies be used to improve existing services or develop new ones, and deployment, i.e. the use of these service by actors in transport.

Fig. 1: Generic Transport Telematic Services

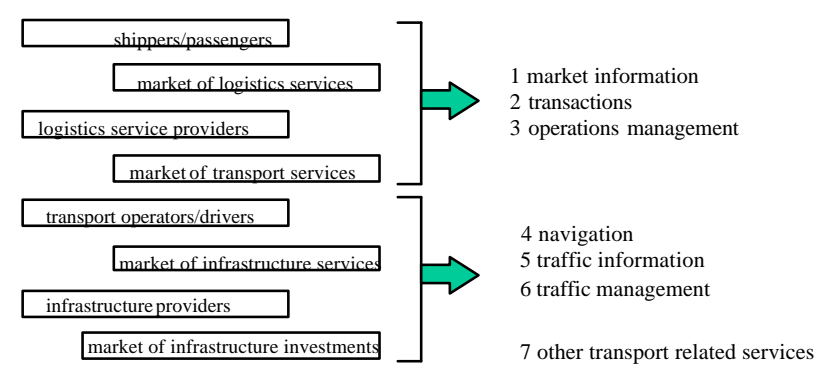

The five elements are correlated. Changes or developments occurring in one element will generally impact the other elements. It is therefore essential for the assessment of policy $\mathbf{e}$ quirements to be aware of what is going on in these elements, to capture signals indicating changes and to consider the relations between these elements. The relations that need to be considered are:

- ICT trends and developments,

- needs of the transport system,

- information needs of actors,

- opportunities for new services,

- barriers to deployment,

- state of the art,

- policy options policy issues,

- impacts or contribution to the CTP. 
Fig. 2: Important subjects and relations

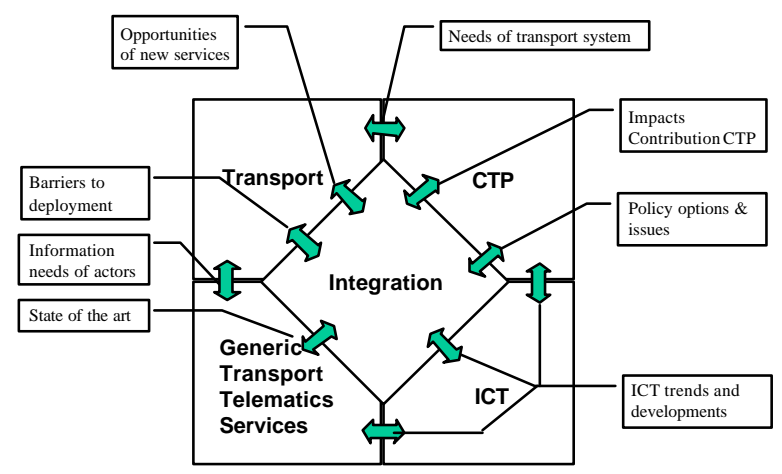

The main issue for policy makers is how to deal with all these elements and relations. In a complex environment with many actors and many fast and simultaneous development it is not only important to maintain a good overview of the major trends, but also to separate short term developments, problems and solutions from developments and opportunities that have structural impact in the long term. The number of relations to consider, the number of political issues to deal with and the amount of information to handle may become enormous. Therefore, policy makers need a tool to help them to gather and structure the relevant information in each step of the policy development process. In the ideal situation, a decomposition of the trends and developments in each of the above mentioned elements and relationships should be related to the different steps in the policy making process. For this purpose, a "stagist"approach is a useful approach.

\section{A framework for assessment of transport information systems policies}

The stagist approach views the policy-making process as composed of a series of steps or sequences (Easton 1965; Parssons 1995). The stagist approach analyses policy in terms of a process beginning with an objective setting activity. The next step is to identify an exhaustive set of alternatives that can attain the policy goal. Once a set of alternatives has been selected, each alternative is evaluated as to how well it meets the policy objective or satisfies social requirements. Given the cost (time, money, energy, etc.) and effectiveness of the alternatives, it is then necessary to evaluate the barriers of the implementation. The results should provide the policy-maker with a full range of possible means for achieving a defined social goal and estimates of the feasibility of implementing the alternatives (Baker, Michaels and Preston 1975).

An outline of the "stagist" or conceptual framework as it has been developed in TRANSINPOL in shown in Figure 3. The basis of the conceptual framework is the relationships identified in the previous section. The objective of the framework is twofold. On the one hand to provide an overview of the factors and elements that influence the integration of information and communication services and to provide insight in the relation between these factors. On the other hand to indicate from what points of view a policy maker can pproach these relations in order to identify policy requirements.

In the TRANSINPOL-study this framework is supported by a large set of schemes and figures as a generic architecture of all relevant perspectives.

Fig. 3: The "stagist" assessment framework

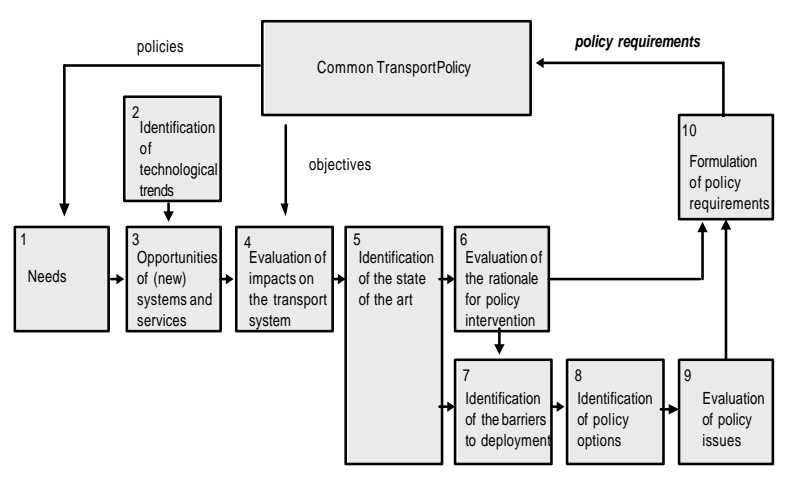

The framework makes a distinction between the strategic issues related to the intergration of ICT in transport opposed to the more or less operational issues. Steps 1 to 6 take into $x$ count the long term needs of the transport system and technological trends to identify the needs for integration and the opportunities offered by the integration. As a result these steps lead to functional policy requirements that specify the need for policy intervention to ensure that the impacts of the integration contribute to the achievement of the CTP objectives. 
However, identifying and formulating functional policy requirements is necessary but not always sufficient to ensure that, at the end, the expected changes will occur. Steps 7 to 9 focus on creating the service environment facilitating the integration of these services and systems in transport. To remove barriers that may slow down or block the integration of information and communication services many options are available to policy makers. The advantages, drawbacks and limitations of policy option and instruments have to be evaluated and compared. Because barriers are in many cases related to each other and policy options may affect various actors, a complex set of impacts and interrelations gives rise to major evaluations, dilemmas and trade-offs that have to be considered by policy makers. The policy issues that can be distinguished in these evaluations can be identified and approached from a transport, industrial, socio-economic, demand side, supply side, economic, technology, legal and institutional or user perspective. The evaluation of barriers, options and policy issues results in operational policy requirements that indicate the needs for policy intervention directly related to the necessity to overcome barriers that might hinder the integration process.

In total, the stagists framework consists of ten stages as shown in Figure 3. In the next section, attention will be devoted to each of the ten steps.

It is clear that the stagist model is an abstraction of the policy analysis and development process. In practice, the various steps may not be fulfilled. Several steps may be performed simultaneously or may be skipped. In reality, the process may be more continuous by nature, where after a particular step, the previous one is reconsidered. The dynamics of the policy making process may be different in each situation, which is always related to certain real-world issues.

\section{Application of the framework}

Apart from this more methodological approach the TRANSINPOL-project also identified actual themes, that are relevant for the current policy making at the EU level. Thus the framework has been applied to several important areas for policy attention. These topics were identified and prioritised during the TRANSINPOL workshops and survey (TNO et al. 1999). In the survey, 700 questionnaires have been distributed among experts on ICT in transport in Europe. In total 132 respondents have returned the questionnaire.

Fig. 4: Prioritisation of twelve areas for policy attention

\begin{tabular}{lr}
\hline Areas for policy attention & $\begin{array}{r}\text { Survey } \\
\text { score }\end{array}$ \\
\hline $\begin{array}{l}\text { Integration of information services between } \\
\text { transport modes and transport operators }\end{array}$ & 3.53 \\
$\begin{array}{l}\text { Use of information and communication } \\
\text { services to influence mobility behaviour }\end{array}$ & 3.47 \\
$\begin{array}{l}\text { Exchange of data between different types of } \\
\text { transport information services }\end{array}$ & 3.38 \\
$\begin{array}{l}\text { Use of ICT in optimisation of infrastructure } \\
\text { utilisation, i.e. traffic management }\end{array}$ & 3.33 \\
$\begin{array}{l}\text { Harmonisation and standardisation } \\
\text { Information Society as major influence on } \\
\text { the dynamics in transport demand patterns }\end{array}$ & 3.11 \\
$\begin{array}{l}\text { Use of ICT for transport safety } \\
\text { Shared use of communication services, } \\
\text { technologies and platforms }\end{array}$ & 2.93 \\
$\begin{array}{l}\text { Implementation of policies and the timing } \\
\text { of policy actions }\end{array}$ & 2.81 \\
$\begin{array}{l}\text { Integration at the application level, devel- } \\
\text { opment of commercial services and human } \\
\text { machine interfaces }\end{array}$ & 2.74 \\
$\begin{array}{l}\text { High level architectures, harmonisation of } \\
\text { information services } \\
\text { Geographical boundaries, areas, networks } \\
\text { etc., i.e. coverage, regions, locations }\end{array}$ & 2.55 \\
\hline
\end{tabular}

The conceptual framework was used to define what needs have to be addressed within each of the above mentioned area for policy attention. As an example, we will elaborate in this section on the topic Integration of information services between modes and operators.

Step 1 Need: Realise co-operative undertakings where there is an apparent benefit for a whole mode or transport chain, not only to offer seamless transport services to passengers and freight, but also to improve efficiency of transport processes. Apart from market information, it will require exchange of information on related to transport operations (capacity of resources and equipment). 
Step 2 Technology Trends: Data exchange standards and formats (e.g. EDIFACT, Internet-technology); group decision tools; advanced simulation and modelling tools.

Step 3 Opportunities: Tools to organise and monitor the shared use of resources and equipment; tools to exchange information relevant to integrate or link business processes in different organisations with each other; tools for objective quality control and quality management along transport chains; tools that can model co-operative undertakings and demonstrate the benefits through simulation; knowledge bases of successful co-operative undertakings (best practice).

Step 4 Impacts: Improvement of chain performance and reduction of costs of non-quality in particular in intermodal and public transport; increased attraction, performance and scale of intermodal and public transport operations.

Step 5 State of the art: Integration of services is extremely rare to find in fragmented transport chains and industries where there are no clear problem owners and no powerful actors.

Step 6 Rationale of policy: An increase in the efficiency and reliability of intermodal transport chains is an important objective of the CTP. Disability of individual firms to initiate cooperation with others, be it due to a lack of experience or a lack of resources that are needed to prepare a co-operation initiative.

Step 7 Barriers: Accommodation of interests is difficult in non-win-win situations; lack of powerful actors; lack of connectivity; Lack/degree of diffusion of advanced ICT.

Step 8 Policy options: Stressing and demonstrating the benefits of cooperation. Provide forums and tools to initiate co-operative ventures. Provide co-operation facilitators (neutral third party that identifies opportunities for co-operation, assesses the scope for co-operation, initiates and manages the co-operation building process). Provide methodologies for the accommodation of interests in cooperative ventures.

Step 9 Policy Issues: Position of SME's; balance between competition and cooperation in transport markets.

Step 10 Functional policy requirement: Need for policy to create incentives or support initiatives for co-operation between operators, especially in a deregulated and competitive environment, contributing to enlarged synergy and interoperability between transport services. Operational policy requirements: standardisation of terminology and technology, harmonisation of transport services and quality levels, rules for liability and responsibilities in chains.

\section{Conclusion}

The value of the stagist approach to the process of policy making is the systematic identification and structuring of the various steps in the formulation of transport policies. It supports policymakers in identifying relevant information for each step. It also facilitated a systematic inventory of relevant issues in the project. Although we realise that the framework described in this paper is rather generic and policy makers have to make a translation to his own specific situation or circumstances, our experiences in workshops and interviews proves the functionality and value of the framework. When users recognise the generic principles presented by the framework and the specific characteristics of their own situation, the framework provided a basis to identify and to evaluate other lines of thinking and new options.

The model can be a starting point for the development of computer aided policy analysis and knowledge systems, focusing on different aspects of information systems transport policies. By using this framework, new projects and experiences can be categorised and evaluated systematically. 


\section{References}

Baker, R. F.; Michaels, R. M.; Preston, E. S., 1975: Public Policy Development. New York/London: John Wiley \& Sons

Easton, D., 1965: A Framework for Policy Analysis. Prentice-Hall, Englewood-Cliffs, N.J.

$F D C, \quad R W S$, TNO Inro, PLS, Technum, NLB, FUNDP, 2000: Synthesis of transport policy requirements for the integration of information, communication and navigation technology in transport, TRANSINPOL Deliverable 7, Paris: FDC

Lasswell, H. D., 1970: The Emerging Conception of Policy Sciences. Policy Science, 1, pp. 3-14

Parssons, W., 1995: Public Policy - An introduction to the theory and practice of policy analysis. Aldershot UK/Brookfield US: Edward Elgar

Sabatier, P. A.; Jenkins Smith, H., 1993: Policy and Learning: A Advocacy Coalition Approach. Boulder, Col.: Westview Press

TNO Inro, Fraunhofer ISI, Technum, 1999: Assessment of transport policy requirements for the system integration information and communication services, TRANSINPOL Deliverable 2, Delft: TNO Inro, September 1999

* The paper was first published on a CD-Rom titled "From Vision to Reality", Proceedings of the World Congress on Intelligent Transport Systems. Turin, Italy, from 6-9 November 2000. (published by ERTICO, ITS America, EU and Vertis)

\section{Contact}

Thierry Verduijn

Netherlands Institute of Applied Geoscience (TNO) TNO Inro

P.O. Box 6041, 2600 JA Delft, The Netherlands Tel.: + 3115269 4884; Fax: + 31152696854 e-mail: tmv@inro.tno.nl

\section{Indikatoren im Rahmen einer Lokalen Agenda 21}

\author{
von Volker Teichert, Forschungsstätte der \\ Evangelischen Studiengemeinschaft
}

In dem Forschungsvorhaben „Indikatoren im Rahmen einer Lokalen Agenda 21" wurde an der Forschungsstätte der Evangelischen Studiengemeinschaft (FEST) Heidelberg im Auftrag der Umweltministerien von Baden-Württemberg, Bayern, Hessen und Thüringen sowie der Landesanstalt für Umweltschutz Baden-Württemberg und des Bayerischen Landesamtes für Umweltschutz ein Indikatorensatz zur Lokalen Agenda 21 entworfen.

Der Auftrag umfasste im Kern folgende Anforderungen:

- Das Indikatorensystem sollte sich auf vorhandene Daten bei den Statistischen Landesämtern, den Landesämtern für Umweltschutz, den Gesundheitsämtern, den Landeskriminalämtern und den örtlichen Ämtern stützen und als Grundlage für die Beschreibung einer nachhaltigen Entwicklung genutzt werden können. Ebenso sollte auf eine Durchgängigkeit von der lokalen bis zur internationalen Ebene gachtet werden.

- Die Zahl der Indikatoren sollte sich auf eine überschaubare Größe konzentrieren, so dass vor allem auch kleinere Kommunen in die Lage versetzt werden, das Indikatorensystem fortzuschreiben.

- Der Indikatorensatz sollte in jeweils drei Kommunen unterschiedlicher Größe und einem Landkreis in den beteiligten Bundesländern im Hinblick auf Praktikabilität und Aussagekraft getestet werden.

- Die erhobenen Indikatorendaten sollten in einer Zeitreihe von mindestens zehn Jahren abgebildet werden, um mögliche Trends ablesen zu können. 